\title{
HYGIENIC SUBSTANTIATION OF OPTIMAL DEBONING OF BROILER CHICKENS IN \\ SAUSAGE PRODUCTION.
}

Tashkent, Tashkent Institute of Advanced Medical Studies

Israilova Gulida Maratovna

\section{SUMMARY}

Currently, in our country, as in all countries with developed poultry farming, there is a tendency to increase the production of poultry meat products, with special attention being paid to the issue of rational use of all protein-containing raw materials for food purposes. The objects of the research were the poultry farm of Yangiyul city. For the study we used chilled, gutted broiler carcasses of II category with lifetime and technological defects, necks from gutted poultry without skin. From the hygienic point of view optimal modes of obtaining meat mass with an undisturbed structure by deboning whole carcasses, necks, skeletons on the plant with elastic working tape are substantiated and expediency of using the meat-bone residue for further mechanical deboning is established. Rational technological parameters (BSC, VUS, CMC) of lumpy meat (pectoral muscles and chicken legs) of chickens for the sausage production have been established.

Key words: food safety, poultry meat, mechanical boning, poultry sausages, protein.

Improvement of the system of quality assurance and food safety is a priority area of state policy. This is evidenced by the "Strategy for Action in five priority areas of development of the Republic of Uzbekistan in 2017-2021" adopted by President Sh. Mirziyev, which was the most important policy document that defined the priority areas of state policy in the medium term.

Food contamination has significant economic consequences and impacts on the health of people around the world. At present, in our country, as in all countries with developed poultry farming, there is a tendency to increase the production of poultry products, with special attention paid to the rational use of all protein-containing raw materials for food purposes.

Introduction of results of researches will provide manufacturers with an instructional-methodical material for internal (industrial) inspection, for production process and will raise responsibility of manufacturers before consumers.

The objects of the research were the bird of the factory in Yangiyul city and the following materials:

- pectoral muscles and meat from chicken broilers' hams;

- meat mass after deboning at the plant with elastic working tape of whole carcasses, necks, skeletons;

- meat bone residue after the deboning of whole carcasses, necks, skeletons on the machine with elastic working tape;

- the finished product containing the meat mass obtained after the deboning of raw materials on the installation with elastic working tape. 
This choice of raw materials is justified by the fact that broiler production accounts for $75 \%$ of the total production volume. Category II broiler carcasses with lifetime and technological defects, gutted poultry necks without skin were used for the study.

The purpose of the study is to develop a method and select the optimal modes of deboning broiler chickens and justify its use for the production of sausages.

In accordance with the objective set, the following tasks were defined:

- Study of technological properties of pectoral muscles and meat from chicken broilers' hams;

- Selection of rational modes of operation of the plant with elastic working tape (IEWT) in order to obtain the meat mass and determine its qualitative parameters;

- development of technology and scientific and technical documentation for the production of sausages from poultry meat.

Scientific novelty. Optimal from the hygienic point of view modes of obtaining meat mass with an undefeated structure by deboning whole carcasses, necks, skeletons on the plant with elastic working tape are substantiated and expediency of using the meat-bone residue for further mechanical deboning is established. Rational technological parameters of lumpy meat (breast muscles and meat from hams) of chickens for the purpose of sausage products production are established.

Practical importance. Combined use of all types of raw materials in poultry products will expand the range of products and increase the production of sausage products.

Result of the research. It has been found that, with complete guttering of poultry, necks are separated, and with cutting and deboning - frameworks, wings, pectoral and tubular bones, which are difficult to manually deboning. In addition, 5\% of the total production volume in the industry is made up of poultry, which is skinny in its fatness, with lifetime and technological defects, and which cannot be sold, but which can be used in the production of poultry products. According to the technology of rational processing, breast muscles and meat from hams are directed to the production of natural semi-finished products, ham products, rolls, and other parts - to mechanical deboning. Research on the quality of mechanical deboning meat is known, but there is limited information available on the technological properties of breast muscles and chicken gammons, which are essential for the production of sausages from poultry meat. Publications on the quality of mechanical deboning show that there is limited use of this raw material in the production of poultry meat products. In our country, optimal deboning is widely used in sausage production in the amount not exceeding $30 \%$ of the volume of raw materials used. In the literature there are data on the use of plants with elastic working tape for deboning of carcasses, they show the expediency of using such plants and the prospects of research in this direction. Undoubtedly, scientific substantiation of a new type of raw material from poultry meat with improved quality indicators will allow to increase the production of sausage products, which is an urgent task for the industry. 
One of the main processes in sausage production is the meat salting. Cooked salt is used as a preservative, flavoring substance, as well as contributing to the increase of technological parameters. In order to facilitate salt penetration into the meat and to speed up the salt process, the breast muscles separated from the bone and the meat from the chicken broilers' hams were shredded on a dagger with a hole diameter of $2-3 \mathrm{~mm}$, then salt was added from $0.5 \%$ to $2 \%$ with an interval of 0.5 water. For the production of semi-smoked sausages from poultry meat the main process will be mixing, as it provides the formation of the structure of sausage minced meat and contributes to the increase in the $\mathrm{BCC}$ to a certain limit. Mixing was carried out on the stirrer EU-06, the speed of rotation is $170 \mathrm{rpm}$. The required degree of homogeneity and formation of structure is achieved in different time. Mixing time varied from $60 \mathrm{~s}$ to $600 \mathrm{~s}$. After separating the most valuable parts (pectoral muscles and meat from hams) from poultry carcasses, there are parts containing up to $25-30 \%$ of the total weight of the parts and $50 \%$ of the meat on the necks. In order to obtain additional quantity of meat with partially undisturbed structure, an installation with elastic working tape was used. In order to substantiate rational operation modes of the unit with elastic working tape, drums with different hole diameters $(1.0 ; 1.5 ; 2.0 ; 3.0$; $5.0 \mathrm{~mm}$ ) were produced. Studies of lumpy meat, meat mass and meat and bone residue were carried out according to the following indicators: mass fraction of moisture, protein, fat, ash, $\mathrm{pH}$ value - according to generally accepted methods, waterbonding capacity (WBC), Grau and Gamma method in the Volovinskaya and Kelman modification, moisture retention capacity (MRC) - according to the method developed by Lyubchenko in the Bolshakov's modification, Uzhakhoy M.K, weight loss and yield - by direct weighing of raw materials and after heat treatment, plasticity $(\mathrm{P})$ - by the area of the spot of pressed meat, shear stress limit (shear stress) with the help of penetrometer mark 1SP - 1, the content of connective tissue by the method of determining oxyproline, the content of muscle protein without protein connective tissue, content of calcium mass fraction by method of titration content of bone mass fraction by dissolution of muscle tissue by $2-\%$ by potassium hydroxide solution, determination of bone particle size by microstructural analysis with the help of the system, determination of muscle fibers size by microstructural analysis. The indicators used are widely used to assess the quality of raw materials and their suitability for the production of finished products and allowed us to determine the rational parameters of the process of obtaining high quality meat mass, which provides the maximum possible yield.

The carried out researches have established, that at addition of a moisture up to 1555 moisture-bonding ability of WBC, moisture retention capacity MRC increased with enhancement in time of mixing from $60 \mathrm{sec}$ to $420 \mathrm{sec}$, then at the further addition of water and mixing the given indicators decreased irrespective of a kind of meat of broilers. The analysis of experimental data showed that the highest values of WBC and MRC are observed when adding 15\% water for pectoral muscles and $10 \%$ for meat with hams and were $70-72 \%$ and $67-69 \%$, respectively, according to MRC 
$69-71 \%$ and $65-66 \%$. Thus, the addition of $15 \%$ moisture for pectoral muscles and $10 \%$ of meat length from hams provides extreme values of technological properties. The addition of moisture and the duration of mixing practically did not influence the $\mathrm{pH}$ value. But the addition of table salt increases the response of the pectoral muscles from 5.6 to 6.39 and the increase of $14 \%$, the meat from hams from 6.2 to 6.6 and the increase of $4 \%$. It should be noted that the $\mathrm{pH}$ value of the pectoral muscles is significantly higher than that of the meat from the hams. When adding chef salt, changes in the $\mathrm{pH}$ of pectoral muscles and pelvic meat were observed. The maximum values of technological parameters were observed when $1.5 \%$ of table salt was added, this amount has the same effect on both breast muscles and meat from hams. Accordingly, the addition of cooking salt to sausages above $1.5 \%$ is not justified, not only from a medical point of view to ensure a healthy diet and reduce latent threats as a risk factor for cardiovascular disease, but also from a technological point of view.

\section{Literature:}

1. V. A. Abaldova, Analysis of mechanical deboning equipment for poultry meat and quality of products. Meat Technologies. - 2013.- No 5.-C. 60-63.

2. Antipova L.V., S.V. Polyanskikh, O.G. Orekhov. Rational use of bone residue in the processing of broiler chickens // Meat Technologies. - 2013. - No 5.- C. 32-34.

3. Bessonova L.P., L.P. Bessonova, N.P. Fazilova. Innovative way to improve the quality of meat products. Meat Industry.2014.-No 7.-C. 4-7.

4. Israilova G.M., Hygiene evaluation of meat products smoking process. «Topical issues of healthy and dietary meals». Pages 61-63. Tashkent 2017

5. Israilova G.M., Microbial semination of sausage products produced by some enterprises of the Republic of Uzbekistan. Collection of lectures and theses. Regional scientific-practical conference dedicated to the "Healthy mother and child year" in 2016, "Dangerous factors affecting population's morbidity and actual problems in their prevention". November 19, 2016, Ferghana city.. Page 198.

6. Kudryashov L.S. Quality assessment of meat raw materials. Meat industry. 2013. - No 2. -C. 43-46. c. 46

7. Maximov D.A. Kulishev B.V., Improvement of the process and equipment for deboning of hams of chicken-broilers: D.A. Maximov, // Meat industry. -2014. No 1. -C. 46-49.

8. Makhonina V.N., Roslikov D.A. On the issue of assessing the quality of poultry meat of mechanical deboning. "Poultry and poultry products" № 1, 2013. 